\title{
Multimodal Discourse Analysis of Advertising Language
}

\author{
Chunli Zhang \\ Foreign Language Department \\ Zaozhuang University \\ Zaozhuang, China
}

\begin{abstract}
With the advent of the information age, the way of information transmission has gone beyond a single form of text symbol. So far, the discourse analysis is basically restricted to the language itself, paying no attention to other meaning expression forms, such as sound, image and animation. However, multimodal discourse analysis breaks this limitation and promotes other meaning expression forms to constitute broader semiotic resources along with linguistic symbols in the construction of meaning. This thesis is a multimodal discourse analysis of advertising language from both lingusitic semiotic mode and image mode. The research combines "multimodal discourse analysis" of linguistics with "advertising" of communication, expanding the new path of advertising communication research and application.
\end{abstract}

Keywords-multimodal discourse analysis; adverting language

\section{INTRODUCTION}

With the advent of the information age, multimodality and multimedia emerge as a trend in people's way of communication, and the way of information transmission has gone beyond a single form of text symbol. So far, the discourse analysis is basically restricted to the language itself, concentrate merely on the intersection of grammatical meaning, psychological understanding and social culture, while paying no attention to other meaning expression forms, such as sound, image and animation. However, multimodal discourse analysis breaks this limitation and promotes other meaning expression forms to constitute broader semiotic resources along with linguistic symbols in the construction of meaning. It can illustrate the generation and communication of meaning thoroughly, and its emergence has greatly enriched the means of discourse analysis.

\section{THE CURRENT SitUATION AND TREND OF ADVERTISING LANGUAGE RESEARCH}

The initial stage of advertising language research started before 1994. The earliest advertising language research papers can be traced back to 1963 when Zhang Wenfeng published "Advertising Language Should Pay Attention to

The thesis is a phased achievement of the Humanistic and Social Science Subject for Institution of Higher Education in Shandong Province (J16WC36) and the Key Subject of Art Science in Shandong Province (1607086).
Standardization" in Language Planning (original title "Character Reform"), and then after a long time of research blank, Zhu Zengpu published "Wonderful Advertising Language" in South Reviews in 1987. Shao Jingmin studied and summarized the advertising language research between 1979 when China began reform and opening up and 1994 in his article "The Current Situation of Advertising Language Research and our Countermeasures". Research findings in this period were relatively few, focusing on the intuitionistic and declarative features of language. Most of the advertising language research took the micro-perspective of pure language and studied the rhetorical devices of language and characteristics of foreign advertising language on the superficial level, including Li Guomin's paper "About Making Paralleled Advertising Language" in1994 and He Yingyu's paper "Study on the Advertising Language of Russian Newspapers" in 1994; or researched advertising language creation in the advertiser's position, borrowing ideas of advertisement writing, such as Wu Daohui's paper "About Advertising Language Creation in 1994 and Tu Echuan's "One of My Advertising Slogan-People's Insurance Covers the Whole World" in 1994. Advertising works in this period included Creativity and Presentation Skills of Advertising Language written by Chu Peicheng and Advertising Language Art edited by Nie Renzhong. All in all, advertising language research before 1994 was still at the beginning and groping stage.

Advertising language research entered its stage of development between 1995 and 2000 when the advertising language researchers expanded their perspective from the original pure linguistics to sociolinguistics, psycholinguistics, communicative linguistics, and so on. For example, Huang Guowen wrote "Analysis of Conversational Implicature in Advertising Discourse in 1997 and Lu Changhuai wrote "Cultural Implications of Advertising Language" in 2000. Moreover, with the prosperity of the market economy, the business world, the advertising world and the language circle emphasized more on the marketing effect and communication effect of advertising language, as discussed in Lu Peihe's "On the Relationship Between Advertising Language and Opening up the Market" in 1995, Ma Bingjun's "On the Conversational Implicature of Commercial Advertising Discourse" in 2000, etc.. Advertising language research began to consciously combine the pure linguistic perspective with other disciplines such as 
advertising, marketing, communication, psychology and pay close attention to the expressiveness and infectivity of advertising language. Some advertising monographs, such as Shao Jingmin's Practical Advertisement Writing and Advertising Language Creation, Cao Zhiyun's Advertising Language Research, Zhang Daojun's Advertising Language Techniques were published in succession in this period, providing theoretical and practical basis for further study of advertising language.

Since 2001, as the society enters a new era of information, media convergence accelerates and new media emerge in an endless stream, which injects fresh vitality into the development of commercial advertising and provides a broader platform for display. The creation and research of advertising language presents a new scene of great variety and prosperity. New perspectives are introduced in understanding the function and meaning of advertising language. Advertising language has gradually become the complex of artistry, practicality, effectiveness and pertinence. Its creative ideas are further broadened and its characteristic of comprehensive, interdisciplinary research perspective has gradually emerged. During this period, research papers on advertising language are not only large in quantity, but also of great improvement in quality. For example, Li Juan et all integrated language translation with marketing in the paper "Translate English Advertisements Effectively, Be More Competitive in New Markets" in 2008; guided by the translation concept of functionalist skopos theory and through the discussion of linguistic form and rhetoric, Lu Mei and Han Li's " Advertising Language Implication and Translation from the Perspective of Skopos Theory" in 2007 elaborated the importance of processing the implied meaning in translation to realize communicative purposes of the advertisement and make it more attractive and persuasive; in 2007 Zhang $\mathrm{Yu}$ analyzed the oxymoron in the paper "Dialectical Logic and Pragmatic Functions of Oxymoron in Advertising English 论", revealing that the surface semantic contradictions were consolidated in deep reasoning meaning and that the oxymoron has its unique pragmatic function. These papers have both academic value and practical significance. In addition, papers on reviewing the existing studies of advertising language comprehensively or in a certain field have also appeared, including Yang Xianshun's "The Development Track of Advertising Language in Contemporary China" in 2004, Li Mi and Ma Caimei's "A Review of Domestic Advertising Translation Studies" in 2005 , etc.. This period has also witnessed many outstanding works in advertising language studies, such as Wang Junyuan's "Advertising Language", Zhang Yinglan's "Rhetorical Principles and Appreciation of Advertising Language", Zhang Xiuxian and Feng Zhang's "Advertising Language Creation and Appreciation", He Xinxiang's "Rhetoric art of Advertising Language" etc.

However, at present domestic advertising language studies are very active but scattered, lacking systematic theory and complete, comprehensive planning and design. Especially in the new situation where new media, multimodality and other modern technologies develop rapidly, the study of advertising language should overcome the shortcomings, meet the challenges, elevate and perfect its theoretical construction and application innovation.

\section{THE THEORETICAL BASIS AND FRAMEWORK OF MulTiMODAL DisCOURSE ANALYSIS}

The main theoretical foundation of multimodal discourse analysis is systemic functional linguistics. To be more specific, "from systemic functional linguistics, multimodal discourse analysis takes in the view that language is social semiotic and meaning potential, holding that other semiotic systems other than language are also the sources of meaning; approves the systematic theory, believing that multimodal discourse itself is also systemic; absorbs the meta-function hypothesis, considering multimodal discourse, the same as discourse containing only linguistic symbols, to be multifuctional, that is to say, multimodal discourse has ideational function, interpersonal function and textual function; embraces register theory, proposing that contextual factors are closely related to the meaning interpretation of multimodal discourse."

In 2009, Zhang Delu constructed an integrated framework for multimodal discourse analysis. This framework includes four levels: cultural level, context level, content level and expression level. The first two levels are basically consistent with the first two levels of systemic functional linguistics. Among them, the cultural level is the key to making multimodal communication possible, endowing the situational context with interpretative power. This level incorporates the ideology composed of people's thinking patterns, living habits and social conventions and the communicative genre that can actualize this ideology. In a specific context, communication is restricted by contextual factors, including the contextual factors determined by the scope, the tenor and the mode of discourse. Simultaneously, the selected genre ought to be achieved in a certain mode of communication in the process.

The third level of the framework, content level, merges and integrates two original levels, namely, the meaning level and the form level. The meaning level is comprised of ideational meaning, interpersonal meaning and textual meaning restricted by the scope, tenor and mode of discourse. At the form level, the form features of different modes correlate with each other and reflect the meaning of discourse together, with each mode having its own form system, such as visual grammar, auditory grammar, etc.

The fourth level is the expression level. In terms of its basic composition, it generally corresponds to the media level in systemic functional linguistics and is reflected by the form level.

\section{Multimodal COMPosition OF AdVERTisement}

As the most important communication tool and thinking tool of human, language has the function of bearing information with large capacity and multiple aspects, thus becomes the main carrier of advertising information. Realization of the communicative function of advertisements relies mainly on linguistic symbols, while other non- 
linguistic semiotics are usually subordinate. According to a structural linguist Saussure, "langue" is an abstract semiotic system, and "parole" is the actual use of "langue". The language used in advertising is, in a strict sense, a parole. In an advertisement, vividly-depicted functions of the product together with advertising service commitment trigger the audience's ideological resonance, attract them and impress them deeply. Thus the charm of advertising language manifests itself. As Mr. Fang Yulin said, "the key to achieving the effect of advertising is to provide the kind of interest commitment or consumption concept that can grasp the marketing point, mostly by using language."

In the book Grammar of the Film Language, Daniel argues that, "all languages are some established rules, some semiotics with complete meaning that are recognized by the society and teach every member of the society to explain. Story-tellers or thinkers should be the first to learn these semiotics and their rules of combination. But things do not remain static. Artists and philosophers can influence the society, introduce new semiotics and rules and discard outdated ones." In advertising, language is also a predetermined rule, and the "semiotics and their rules of combination" take the form of a multimodal audio-visual combination of sound, image, subtitle and montage grammar. Moreover, this combination is not static, and new symbols and rules are constantly improved and updated in the spatial and temporal structure of advertising.

The famous semiologist $\mathrm{S}$ Lange suggests that communication semiotics used by humans can be divided into two categories: one is the reasoning semiotics, that is, linguistic semiotics, and the other is the representation semiotics, that is, non-linguistic semiotics. Advertising that relies on a variety of modes for information communication (represented by television advertising) mainly consists of linguistic system and non-linguistic system. Linguistic system is composed of modes like voice and text which includes words, phrases and sentences while non-linguistic system consists of modes like image and nonverbal sound.

\section{MUlTimOdAl DisCOURSE ANALYSIS OF ADVERTISING DISCOURSE}

A variety of modes are often used in the advertising strategy. For example, sound, image and language are mainly used in television advertising; sound is usually used in broadcasting; a case demonstration or display at a trade fair or supermarket may also involve gustatory mode (tasting food) or olfactory mode. Statistically, however, the majority of information is still transmitted in language mode and image mode.

\section{A. The Analysis of Linguistic Semiotic Mode}

Language semiotics is the primary mode of meaning expression, the main research object of discourse analysts as well as the main carrier of information transmission. In order to spread and enhance the brand image of "Discovery Channel", language semiotics, in other words the linguistic semiotic mode, are used as media to transmit information. From a communicative point of view, the person who raises a question is a "questioner", and the person who answers the question is a "respondent". "Questioning" in advertising mainly takes three forms:

- the complete non-interrogative sentence;

- the complete wh-question;

- Elliptical sentence.

Whichever form the "questioning" takes, it should be related to the product the advertiser sells and its purpose should be transparent to the audience. The advertiser, as the questioner, raises three how-questions, similar to whquestions, which stimulate readers' interest and their active thinking to seek the answers to these questions. In the end, the trademark "Discovery Channel" is marked in bold, which is an important information: placing the trademark information at the end of the text allows the audience to deepen the impression, which accords with the "end-weight principle" or "unmarked focus" called by linguists; for language users, the content at the end of the sentence being emphasized and highlighted means the speaker's recognition and strong recommendation of the "Discovery Channel".

\section{B. The Analysis of Linguistic Semiotic Mode and Image Mode}

Image is an important semiotic mode, which can well display all kinds of experiential events besides its own semiotic system. That is to say, images can reproduce all kinds of entities besides their own symbols and reveal the complex relationships among these entities. In the research on the concept and meaning of functional grammar, according to Kress \& Van Leeuwen, representational metafunction is divided into two components: one is conceptual reproduction, corresponding to the relational and existential process described in functional grammar; the other is narrative representation, covering three main categories which are action, reaction, speech and mental processes. Narrative reproduction of the image shows the facts displayed by all the images in the picture.

Interactive meaning in multimodal discourse corresponds to the interpersonal meaning of functional grammar. Kress \& Van Leeuwen proposes that clearly the interactive meaning refers to the close relationship among the designers, the objects represented and the viewers of image. On the basis, it also shows the viewers' clear opinion of the symbolic things. In the process of realizing interaction, four main factors are involved, which are social distance, modality, contact and attitude. Analysis on modality and social distance will be emphasized here. Through the analysis of pictures, it can be found that modality is an external form of expression, or in other words, the interplay of color, detail and depth. Depending on sensory coding orientations, an image has three levels of modality: high, middle and low, and the color saturation is obviously a high sensory modality.

The compositional meaning of multimodal discourse equals to the textual meaning in functional grammar. According to Kress \& Van Leeuwen, compositional meaning should follow three principles: information value, salience 
and framing. Information value mainly refers to the corresponding value displayed by the various components placed at different positions: left or right, top or bottom, center or margin. They believe if some elements are placed at the top, then they are "ideal", while other elements placed at the bottom are "real"; similarly, elements on the left are "given information", on the right "new information". Martin \& Rose also hold the view of the intermediate and center structure value of an image, dividing the compositional structure into the center and the edge, with information in the center being the most salient information.

\section{CONCLUSION}

This research integrates advertising language and other related modes, showing not only the roles played by the language mode, including voice and text, in the process of meaning exchange but also the effects of other modes such as image, music, color in the same process, makes the advertising discourse interpretation more comprehensive and more accurate and then discovers how to use multiple modes comprehensively to achieve the purpose of advertising information transmission and social communication. In this sense, it can be said that this study not only promotes linguistic research, but also deepens the understanding of other related disciplines such as communication, sociology and semiotics. What's more, this research can also promote the branch construction of linguistics and, by combining "multimodal discourse analysis" of linguistics with "advertising" of communication, expand the new path of advertising communication research and application.

\section{REFERENCES}

[1] Cook, G. \& Seidlhofer,B. Principles \& Practice in Applied Linguistics. Oxford: Oxford University Press, 1995.

[2] Cook, YY.The Discourse of Advertising. London: Routledge, 1995.

[3] Halliday, M.A.K.\&Hasan, R. Language, Context and Text: Aspects of Language in a Social Semiotic Perpective. Geelong, Vic: Deakin University Press, 1985.

[4] Halliday, M.A.K.\&Matthiessen, C.M.L.N. Introduction to Functional Grammar. London: Edward Arnold, 2004.

[5] Seollon, R.\&Levine, P. Multimodal Discourse Analysis as the Confluence of Discourse and Technology. Georgetown University Press, 2004.

[6] Williamson, J. Decoding Advertisements: Ideology and Meaning in Advertising. London: Martin Boyars, 2000. 